OPEN ACCESS

Edited by:

Oswaldo Hernandez-Hernandez, Instituto de Investigación en Ciencias

de la Alimentación (CIAL), Spain

Reviewed by:

Merichel Plaza

University of Alcalá, Spain

Ren-You Gan,

Shanghai Jiao Tong University, China

*Correspondence: Juan C. Morales jcmorales@ipb.csic.es Francisco J. Plou fplou@icp.csic.es

Specialty section This article was submitted to Nutrition and Food Science Technology,

a section of the journal

Frontiers in Nutrition

Received: 13 November 2018 Accepted: 01 March 2019 Published: 22 March 2019

Citation:

Gonzalez-Alfonso JL, Peñalver P, Ballesteros AO, Morales JC and Plou FJ (2019) Effect of

$\alpha$-Glucosylation on the Stability, Antioxidant Properties, Toxicity, and

Neuroprotective Activity of

(-)-Epigallocatechin Gallate.

Front. Nutr. 6:30.

doi: 10.3389/fnut.2019.00030

\section{Effect of $\alpha$-Glucosylation on the Stability, Antioxidant Properties, Toxicity, and Neuroprotective Activity of (-)-Epigallocatechin Gallate}

\author{
Jose L. Gonzalez-Alfonso ${ }^{1}$, Pablo Peñalver ${ }^{2}$, Antonio O. Ballesteros ${ }^{1}$, Juan C. Morales ${ }^{2 *}$ \\ and Francisco J. Plou ${ }^{1 *}$ \\ ${ }^{1}$ Instituto de Catálisis y Petroleoquímica, CSIC, Madrid, Spain, ${ }^{2}$ Instituto de Parasitología y Biomedicina López-Neyra, CSIC, \\ Granada, Spain
}

(-)-Epigallocatechin gallate (EGCG), the predominant catechin ( $\geq 50 \%)$ in green tea (Camellia sinensis), displays several bioactive properties but its stability and bioavailability are low. In this work, the properties of two $\alpha$-glucosyl derivatives of EGCG ( $3^{\prime}$ - and 7-O- $\alpha$-D-glucopyranoside), obtained by enzymatic synthesis, were assessed. The $\alpha$-glucosylation enhanced the $\mathrm{pH}$ and thermal stability of EGCG. The analysis of scavenging activity toward ABTS + radicals showed that the $\alpha$-glucosylation at C-7 of A-ring caused a higher loss of antioxidant activity compared with the sugar conjugation at C-3' of B-ring. The $3^{\prime}$-glucoside also showed higher potential to alleviate intracellular reactive oxygen species (ROS) levels and to boost REDOX activity. The toxicity of EGCG and its monoglucosides was tested in human SH-S5Y5 neurons, RAW 264.7 macrophages, MRC5 fibroblasts, and HT-29 colon cancer cells. Interestingly, the $3^{\prime}-\mathrm{O}-\alpha$-D-glucoside increased the viability of neural cells in vitro $(2.75$-fold at $100 \mu \mathrm{M})$ in the presence of $\mathrm{H}_{2} \mathrm{O}_{2}$, whilst EGCG gave rise only to a 1.7-fold enhancement. In conclusion, the $\alpha$-glucoside of EGCG at C-3' has a great potential for nutraceutical, cosmetic and biomedical applications.

Keywords: glycosylation, tea polyphenols, antioxidants, catechins, neuroprotective properties

\section{INTRODUCTION}

Plant polyphenols are gaining relevance due to their capacity to delay the appearance of certain degenerative diseases and pathological processes such as Alzheimer's and Parkinson's diseases, schizophrenia, cancer, chronic inflammatory disease, atherosclerosis or myocardial infarction (1-3). Their action is based on the enhancement of the antioxidant system due to their ability to reduce the level of reactive oxygen species (ROS) (4). Many polyphenols are lipophilic scaffolds with rapidly conjugated phenolic $\mathrm{OHs}$ that exhibit poor absorption in vivo, giving rise to a very low concentration in the circulatory streams (5).

Several polyphenols appear glycosylated in nature $(4,6)$ and the sugar moiety seems to play a major role in their solubility (7), partition coefficient (8), protection from oxygen, $\mathrm{pH}$, temperature and/or light (9), absorption (10,11), bioavailability (12), and bioactivity (13). Several studies demonstrated that glycosylation facilitates the diffusion of polyphenols into intestinal enterocytes $(12,14)$. Other investigations have shown that deconjugation of the glycosyl moiety of glycosylated 
flavonoids favors cellular uptake by enterocytes $(15,16)$. Despite this controversy in the role of glycosylation on bioavailability, there is some consensus that glycosylation increases the stability of polyphenols during gastrointestinal transit after ingestion (17) and also during storage (18). In fact, glycosylation is being exploited as a tool to improve the properties of polyphenols (7, 19-22). Enzymatic synthesis is gaining importance due to its selectivity and the environmentally friendly reaction conditions (23-25).

(-)-Epigallocatechin gallate (EGCG) is the predominant catechin $(\geq 50 \%)$ in green tea (Camellia sinensis). It possesses antioxidant (26), antihypertensive (27), antitumoral (28, 29), bactericidal (30), and anti-inflammatory (31) bioactivity, among others. However, EGCG undergoes rapid degradation in aqueous solutions (32) resulting in a low bioavailability (33). The two main processes involved in the instability of EGCG are epimerization and oxidative coupling (34). In order to increase its stability and bioavailability (35), and to reduce its astringency for food applications (36), the glycosylation of EGCG has been explored by several groups, mostly by the use of enzymatic catalysis (37-39). Recently, our group reported the enzymatic synthesis of various $\alpha$-glucosyl derivatives of EGCG by a transglycosylation reaction catalyzed by a cyclodextrin glucanotransferase (CGTase, EC 2.4.1.19) (40). Two main $\alpha$-Dglucosides of EGCG were isolated and chemically characterized: EGCG $33^{\prime}-\mathrm{O}-\alpha-\mathrm{D}$-glucopyranoside (1) and EGCG 7-O- $\alpha-\mathrm{D}$ glucopyranoside (2).

In the present work, we have analyzed the effect of $\alpha$ glucosylation on several properties of EGCG, in particular the $\mathrm{pH}$ and thermal stability, the antioxidant and REDOX activities, the toxicity toward several cell lines and the neuroprotective activity. Consequently, the influence of the position of glycosylation on such properties was assessed.

\section{MATERIALS AND METHODS}

\section{Enzyme and Reagents}

(-)-Epigallocatequin gallate (EGCG) was acquired from Zhejiang Yixin Pharmaceutical Co. (Zhejiang, China). Toruzyme 3.0L, a commercial preparation of cyclodextrin glucanotransferase (CGTase) from Thermoanaerobacter sp., was kindly provided by Novozymes. Partially hydrolyzed starch from potato (Passelli SA2) was from Avebe (Foxhol, The Netherlands). ABTS [2,2'-azino-bis(3-ethylbenzothiazoline-6-sulphonic acid)] and (R)-Trolox (6-hydroxy-2,5,7,8-tetramethylchroman-2carboxylic acid) were purchased from Sigma Aldrich. All other reagents and solvents were of the highest available purity and used as purchased.

\section{Stability Assays}

EGCG and its glucosylated derivatives were dissolved at $4 \mathrm{mg} / \mathrm{mL}$ in $20 \mathrm{mM}$ sodium phosphate buffer $(\mathrm{pH}$ 6.7) and incubated at $60^{\circ} \mathrm{C}$. At intervals, aliquots of $150 \mu \mathrm{L}$ were withdrawn, diluted 2-fold with water and passed through nylon filters $(13 \mathrm{~mm}, 0.45 \mu \mathrm{m})$. The remaining concentrations of EGCG or its glucoside were analyzed by HPLC.

\section{Trolox Equivalent Antioxidant Capacity (TEAC) Assay}

The ABTS ${ }^{+}$was generated from ABTS solution $(7 \mathrm{mM})$ with potassium persulfate $(2.45 \mathrm{mM})$ for $15 \mathrm{~h}$. The radical cation absorbed at $734 \mathrm{~nm}$ and was stable for 2 days. ABTS ${ }^{+}$was diluted in ethanol to $0.7 \pm 0.02$ absorbance units at $734 \mathrm{~nm}$. Addition of antioxidants to the pre-formed radical cation reduces it to ABTS thus decreasing the absorbance. Twenty microliter of antioxidant solution (between 20 and $210 \mu \mathrm{M}$ ) was added to $230 \mu \mathrm{L}$ of adjusted ABTS ${ }^{+}$solution. The decrease of absorbance of the ABTS ${ }^{+}$solution was monitored at $734 \mathrm{~nm}$ during $6 \mathrm{~min}$ using a microplate reader (model Versamax, Molecular Devices). The decrease of absorbance was determined measuring the area under the curve. (R)-Trolox was used as a reference antioxidant. The TEAC value was expressed as the concentration $(\mu \mathrm{M})$ at which the compound decreases the same absorbance as $1 \mu \mathrm{M}(\mathrm{R})$-Trolox.

\section{Cell Cultures}

SH-S5Y5 neurons were cultured in collagen-pretreated petri-dishes with DMEM-F12 medium supplemented with penicillin/streptomycin and 10\% inactivated fetal bovine serum (iFBS). RAW 264.7 macrophages and HT-29 colon cancer cells were cultured in DMEM high glucose medium supplemented with penicillin/streptomycin and 10\% iFBS. MRC5 were cultured in DMEM low glucose medium supplemented with glutamine, penicillin/streptomycin and $10 \%$ iFBS.

\section{Cell Viability Assays}

Neuron assays were done in collagen-pretreated 96 well plates by seeding $2 \times 10^{4}$ neurons per well in a $100 \mu \mathrm{L}$ volume and with $24 \mathrm{~h}$ of incubation before the compound addition. Macrophage assays were done in 96 well plates by seeding 2.5 $\times 10^{4}$ macrophages per well in a $100 \mu \mathrm{L}$ volume with $4 \mathrm{~h}$ of incubation before the compound addition. MRC5 and HT-29 assays were done in 96 well plates by seeding $5 \times 10^{4}$ cells per well in a $100 \mu \mathrm{L}$ volume and with $24 \mathrm{~h}$ of incubation before the compound addition. Tested compounds dissolved in DMSO were then added at different final concentrations $(100,10$, and $1 \mu \mathrm{M})$ to determine compound toxicity. Final DMSO percentage in each cell was adjusted to $1 \%$. Cell viability was evaluated $24 \mathrm{~h}$ (SHSY5Y and RAW 264.7 cells) or 48 h (MRC5 and HT-29 cells) after compounds addition by mitochondrial MTT assay, according to manufacturer.

\section{Measurement of Reactive Oxygen Species (ROS)}

Reactive oxygen species (ROS) levels were evaluated using the ROS-sensitive $\mathrm{H}_{2}$ DCFDA staining method (Sigma, St. Louis, MO, USA). The intracellular ROS level was determined on SH-SY5Y neuroblastoma cells that were cultured, plated and compound-treated as described previously for the cell viability assay. The protective effect of the EGCG derivatives on $\mathrm{H}_{2} \mathrm{O}_{2}$ induced oxidative stress was assayed after a short pre-incubation time of the compounds $(2 \mathrm{~h})$ followed by a short incubation with $\mathrm{H}_{2} \mathrm{O}_{2}(100 \mu \mathrm{M}, 2 \mathrm{~h})$. The intracellular ROS generation of each compound alone, without $\mathrm{H}_{2} \mathrm{O}_{2}$ treatment, after $6 \mathrm{~h}$ 
of incubation, was also evaluated. Following treatments, the

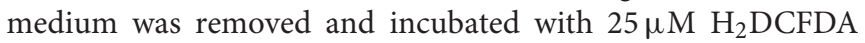
for $2 \mathrm{~h}$ at $37^{\circ} \mathrm{C}$ in the dark. $\mathrm{H}_{2}$ DCFDA, a cell permeable nonfluorescent, is de-esterified intracellularly and turns to the highly fluorescent permeant molecule 2,7-dichlorofluorescein (DCF) in the presence of intracellular ROS upon oxidation. Fluorescence intensity was measured at an excitation wavelength of $485 \mathrm{~nm}$ and an emission wavelength of $530 \mathrm{~nm}$ using a multimode microplate reader (TECAN, Männedorf, Switzerland).

\section{Mitochondrial Oxidation-Reduction (REDOX) Activity}

The analysis of REDOX activity was performed using the fluorogenic oxidation-reduction indicator Resazurin (Life Techonologies Inc., Rockville, MD, USA). The REDOX activity level was determined on SH-SY5Y cells that were cultured, plated and compound-treated as described previously. After treatments, resazurin dissolved in water at a final concentration of $5 \mu \mathrm{M}$ was added to the wells, and the fluorescence intensity was examined at an excitation of $530 \mathrm{~nm}$ and an emission of $590 \mathrm{~nm}$. The plate was incubated for $2 \mathrm{~h}$, and then fluorescence was measured using a multimode microplate reader (TECAN, Männedorf, Switzerland).

\section{Neuroprotective Properties}

EGCG and the corresponding glucosides were assayed in vitro in cell cultures to determine their neuroprotective activity. SHS5Y5 neurons were determined on SH-SY5Y cells that were cultured, plated and compound-treated as described previously. EGCG and its glucosides dissolved in DMSO were added at three concentrations $(1,10$, and $100 \mu \mathrm{M})$ and incubated for $10 \mathrm{~min}$ before the addition of hydrogen peroxide $(100 \mu \mathrm{M})$. Cell viability was evaluated $24 \mathrm{~h}$ after compound addition by mitochondrial MTT assay. Neuron recovery was calculated by normalizing the results from $\mathrm{H}_{2} \mathrm{O}_{2}$-neuron viability to the $\mathrm{H}_{2} \mathrm{O}_{2}$ positive control.

\section{Statistical Analysis}

For the determination of antioxidant capacity (TEAC assay), experiments were performed in triplicate. The standard deviations of TEAC values were calculated from the slope of linear regressions of the curves representing decrease of absorbance vs. concentration. The significant differences between the values were calculated with a $t$-test of slopes and their standard deviations, considering $n$ the number of linear regression points.

For the cell viability assays, analysis of ROS, mitochondrial oxidation-reduction activity and neuroprotective activity, averages and standard deviations of at least eight different readings from various experiments were calculated. Welch's $t$-test for samples with unequal variance (previously tested by one way ANOVA in SigmaPlot 13.0) was made to perform the statistical analysis, considering significant differences when $p<0.05$.

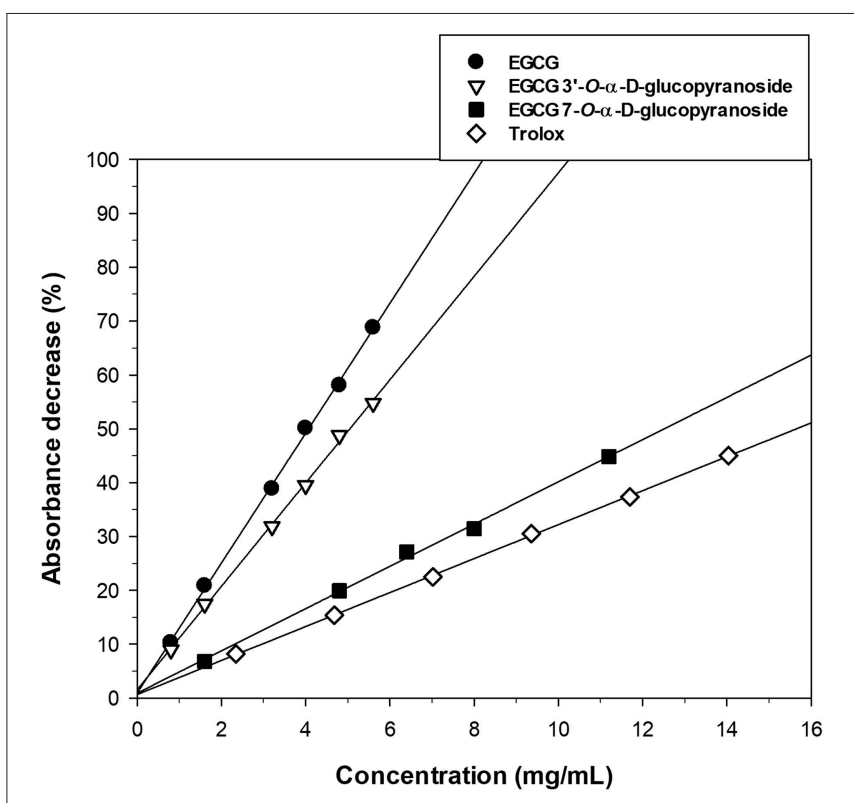

FIGURE 2 | Effect of EGCG and its $\alpha$-glucosides 1 and 2 on ABTS+ reduction. In the assay, Trolox was used as antioxidant reference compound.

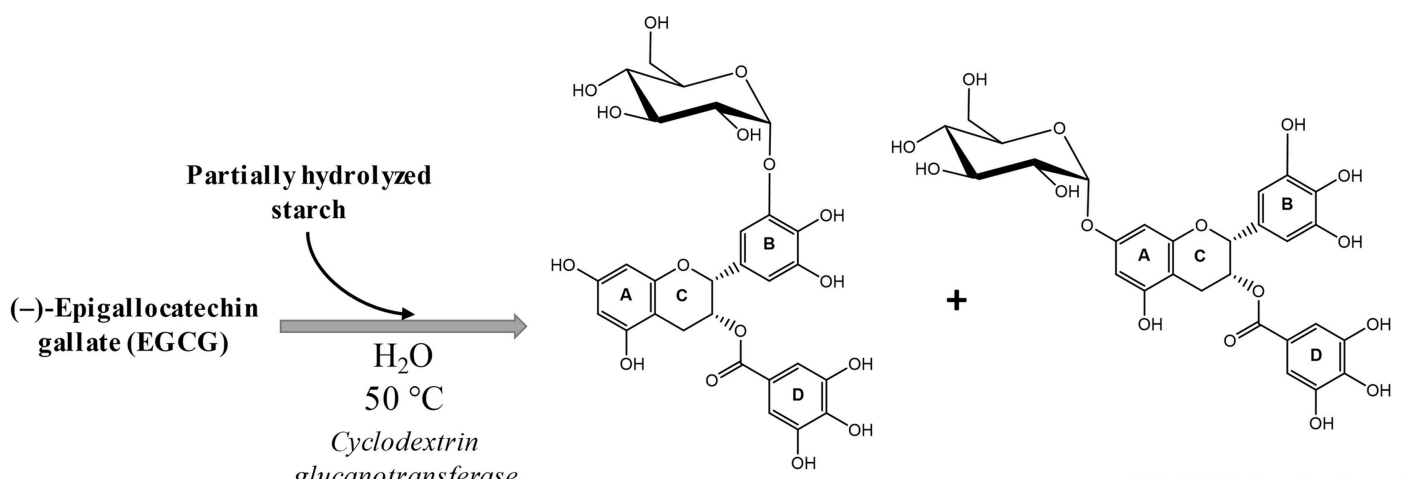

EGCG 3'-O- $\alpha$-D-glucoside (1)

EGCG 7-O- $\alpha$-D-glucoside (2)

FIGURE 1 | Scheme of the glucosylation of EGCG and the structure of the two main products: epigallocatechin gallate $3^{\prime}-O-\alpha$-D-glucopyranoside (1) and epigallocatechin gallate 7-O- $\alpha$-D-glucopyranoside (2). 
TABLE 1 | TEAC values of EGCG and its $\alpha$-glucosides.

\begin{tabular}{lccc}
\hline Compound & $\begin{array}{c}\text { Slope of linear } \\
\text { regression }\end{array}$ & $\mathbf{R}^{\mathbf{2}}$ & TEAC \\
\hline Trolox & $3.22 \pm 0.02$ & 0.996 & $1.00 \pm 0.02$ \\
EGCG & $12.1 \pm 0.1$ & 0.999 & $0.27 \pm 0.02$ \\
EGCG 3'-O- $\alpha$-D-glucopyranoside & $9.97 \pm 0.20$ & 0.996 & $0.32 \pm 0.02^{*}$ \\
EGCG 7-O- $\alpha$-D-glucopyranoside & $4.04 \pm 0.20$ & 0.999 & $0.80 \pm 0.04^{*}$
\end{tabular}

The data is expressed as mean $\pm S D\left(n=6,{ }^{*} p<0.01\right.$ vs. EGCG).

\section{RESULTS AND DISCUSSION EGCG Glucosylation and Effect on Antioxidant Properties}

The synthesis of various $\alpha$-glucosyl derivatives of (-)epigallocatechin gallate (EGCG) was performed following a previous work developed in our laboratory (40). The reaction takes place at $50^{\circ} \mathrm{C}$ catalyzed by cyclodextrin glucanotransferase (CGTase) from Thermoanaerobacter sp., using hydrolyzed potato starch as glucosyl donor (Figure 1). The reaction was performed in water (no buffer), as the maximum stability of EGCG was found in this solvent (40). Two main monoglucosides were the main products and were chemically characterized by combining MS 2D-NMR methods. The major derivative was epigallocatechin gallate $3^{\prime}-\mathrm{O}-\alpha-\mathrm{D}$-glucopyranoside $(1)$ and the minor epigallocatechin gallate $7-\mathrm{O}-\alpha-\mathrm{D}$-glucopyranoside (2).

We studied the antioxidant activity of the two glucosylated derivatives by the TEAC assay to assess the role of the different phenolic groups on the EGCG properties. The results of the assay are represented in Figure 2. The incorporation of a $\alpha$ glucosyl moiety to the position 7 of A-ring caused a higher loss of antioxidant activity than in position $3^{\prime}$ of B-ring. The TEAC values, calculated from the slopes of linear regressions of Figure 2, are summarized in Table 1. In all cases the TEAC values were lower than that obtained for Trolox.

As shown in Figure 2, the glucosylation at the $3^{\prime}$-position has a slight influence on the scavenging activity of EGCG toward $\mathrm{ABTS}^{+}$radicals. In this context, it has been reported that the ortho-trihydroxyl group (at positions $\mathrm{C}-3^{\prime},-4^{\prime}$, and $-5^{\prime}$ ) at B-ring and the gallate moiety at C-3 of A-ring are the most important structural features for scavenging free radicals by EGCG (38, 41). Our results compare well with those described by Nanjo et al. using the DPPH radicals assay $(41,42)$ However, it must be considered that the free radical scavenging capacity of tea catechins and their derivatives is radical-dependent (32). In the case of DPPH radical scavenging, it has been demonstrated that both the $4^{\prime}-\mathrm{OH}$ at B-ring and the $4^{\prime \prime}-\mathrm{OH}$ at the galloyl moiety are essential to maintain antioxidant activity $(39,43)$.

\section{Stability of EGCG Glucosides}

It is well-reported that the stability of EGCG in aqueous solutions is rather limited $(37,44,45)$. The two main processes involved in the degradation of EGCG are epimerization and oxidative coupling (34). The stability of EGCG is concentration-dependent

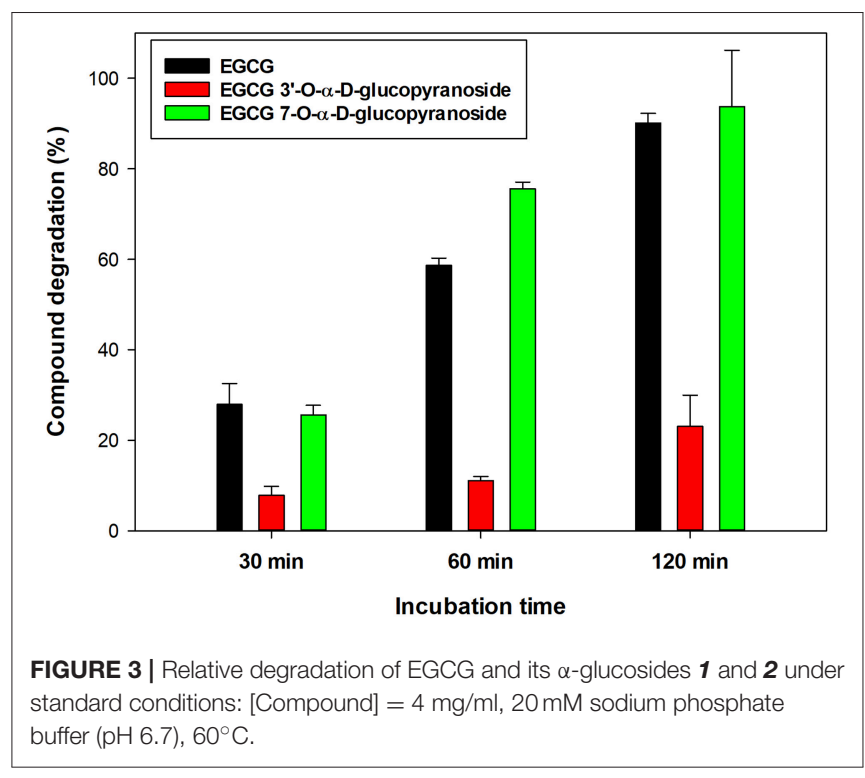

and can be also influenced by temperature, $\mathrm{pH}$ and the amount of oxygen in the solution, among other parameters (32).

The stability of EGCG and its two monoglucosides in a buffered solution was comparatively studied. The compounds $(4 \mathrm{mg} / \mathrm{mL})$ were dissolved in $20 \mathrm{mM}$ phosphate buffer $(\mathrm{pH}$ 6.7) and incubated at $60^{\circ} \mathrm{C}$. As shown in Figure 3, the EGCG was degraded about 4 -fold faster than the monoglucoside 1 . The degradation process was concomitant with the appearance of (-)-gallocatechin gallate (GCG) as a result of EGCG epimerization (data not shown). The color of the solutions became brown upon incubation, as a consequence of the formation by oxidative coupling of dimers and compounds of higher molecular-weight (46).

After $1 \mathrm{~h}$ incubation, 59\% of initial EGCG and 76\% of monoglucoside 2 had disappeared, in contrast with only 11\% of the monoglucoside at $3^{\prime}-\mathrm{OH}$. In this context, Noguchi et al. reported that the 5-O- $\alpha$-D-glucopyranoside of EGCG was about 1.5-fold more stable than the parent compound at $\mathrm{pH} 7.0$ and $80^{\circ} \mathrm{C}$ (36). Kitao et al. reported that the $\alpha$-monoglucoside at C-4' of B-ring was also substantially more stable than EGCG (37). Therefore, the glycosylation of EGCG in position $3^{\prime}$ of Bring increases significantly the resistance of EGCG to $\mathrm{pH}$ and thermal degradation.

\section{Toxicity of EGCG Glucosides}

The toxicity of EGCG and the isolated monoglucosides $\mathbf{1}$ and 2 was tested in four cell lines (human SH-S5Y5 neurons, RAW 264.7 macrophages, MRC5 fibroblasts and HT-29 colon cancer cells). The viability of cells in the presence of the compounds was determined at three concentrations $(1,10$, and $100 \mu \mathrm{M})$. The final DMSO percentage in each cell was adjusted to $1 \%(\mathrm{v} / \mathrm{v})$. The values were referred to the control (cells containing $1 \%$ DMSO). As shown in Figure 4, EGCG and its glucosides were not significantly toxic for any of the examined cell lines, except for the parent compound EGCG at $100 \mu \mathrm{M}$ concentration in HT-29 colon cancer cells (Figure 4D). 

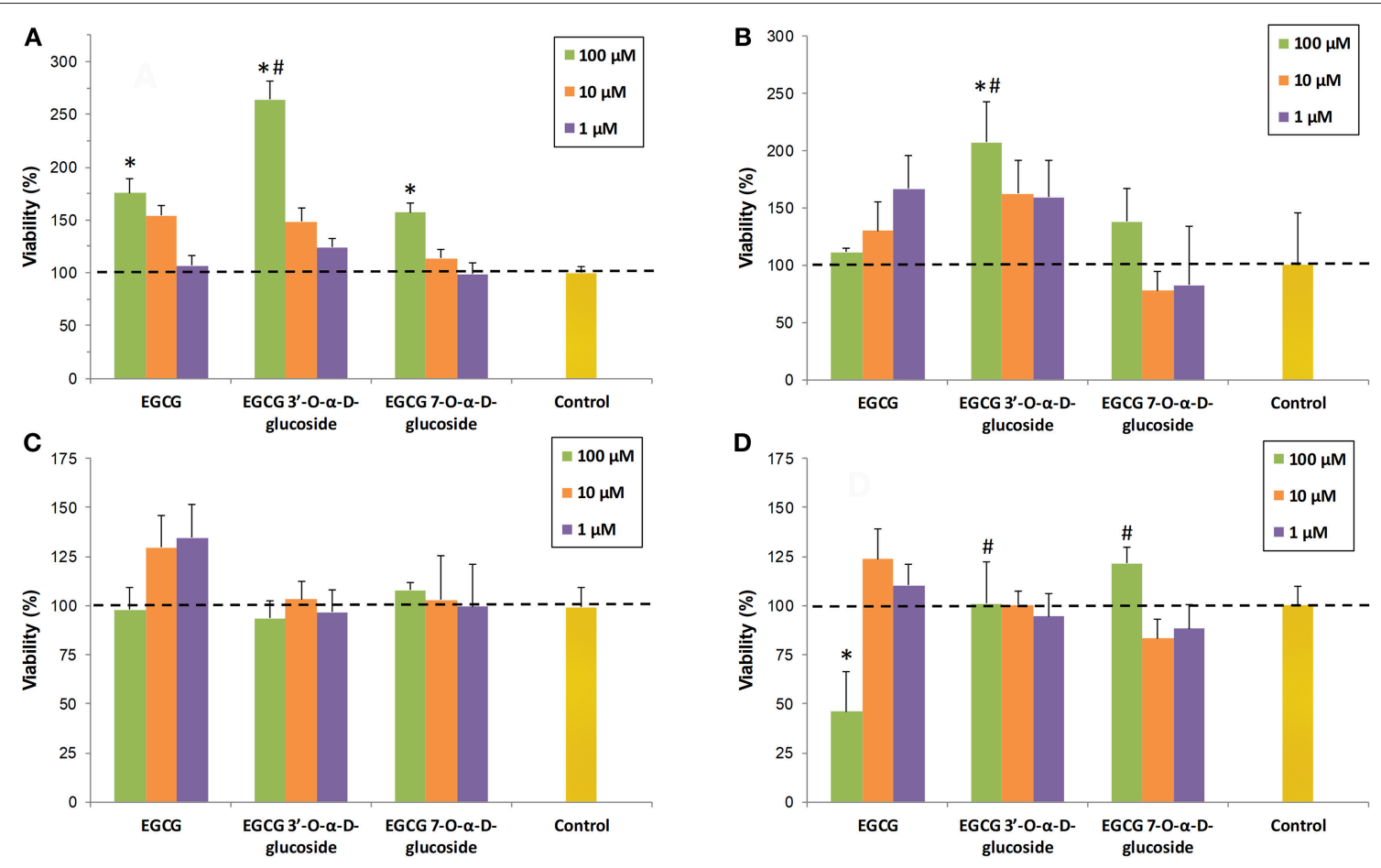

FIGURE 4 | Cell viability assays in presence of EGCG and its $\alpha$-glucosides 1 and 2 on: (A) SH-SY5Y neuronal cells; (B) RAW 264.7 macrophages; (C) MRC5 fibroblasts; (D) HT-29 colon cancer cells. The values are referred to the control (cells containing $1 \%$ DMSO). The data is expressed as mean \pm SD ( $n=8$, ${ }^{\star} p<0.05$ vs. control group; \#p < 0.05 vs. EGCG (100 $\mu \mathrm{M})$ group).

The cytotoxic effect on HT-29 cancer cells correlates well with previous reports on the specific pro-oxidant action of catechins toward cancer cells (47), which seems to be modulated by sirtuin 3 (SIRT3) (48). Thus, green tea catechins (including EGCG) may exert pro-oxidant activity in cancer cells leading to cell death but antioxidant effects in normal cells (49).

We have observed that the presence of a glucose unit in a natural phenolic compound such as resveratrol, like in piceid (3$\beta$-glucoside of resveratrol), also decreases the intrinsic toxicity of the parent molecule in human embryonic kidney cells (HEK-293) (21). However, this is not a general trend since piceid is more toxic than resveratrol for HT-29 and breast adenocarcinoma MCF-7 cancer cells. The differences in cellular uptake of the compounds could be related to the observed toxicity, especially if the glucose transporters are playing a role in the entrance of the glucoside derivatives.

\section{ROS and REDOX Activity of EGCG Glucosides}

Once established the safety of EGCG and EGCG glucosides toward SH-SY5Y neuroblastoma cultures, their potential to alleviate intracellular ROS levels or to boost intracellular REDOX activity was determined (50). The former assays were carried out in the presence of hydrogen peroxide as intracellular ROS trigger. Basal ROS levels (Figure 5A1) were measured from the fluorescence intensity of DCF as it is explained in the Experimental section. As a rule, all compounds produced a doseresponse decrease in ROS levels, but this effect was significantly greater for EGCG and EGCG $3^{\prime}-O-\alpha-\mathrm{D}$-glucoside, compared to EGCG 7-O- $\alpha$-D-glucoside (Figure 5A2). Remarkably, the treatment with $100 \mu \mathrm{M}$ EGCG and its $3^{\prime}-\alpha$-D-glucoside lowered ROS levels to nearly $50 \%$ of the non-stimulated cells value.

Regarding REDOX activity, $\mathrm{H}_{2} \mathrm{O}_{2}$ treatment led to a small decrease of REDOX compared to control cells, which was attenuated by a $100 \mu \mathrm{M}$ pretreatment with all the compounds screened (Figure 5B2). Bigger differences were observed in REDOX activity between control cells and pretreatment with each compound alone for $6 \mathrm{~h}$, where all the derivatives at $100 \mu \mathrm{M}$ were able to increase the basal REDOX activity regardless the treatment concentration (Figure 5B1).

\section{Neuroprotective Activity of EGCG Glucosides}

EGCG has arisen a lot of interest as a potential therapeutic agent in the prevention of neurodegenerative diseases (51-53). This ability is related with its antioxidant, radical scavenging, anti-apoptotic and anti-inflammatory properties (54). Several studies confirmed the potential of EGCG to promote healthy aging, suppress cognitive dysfunction, increase learning ability and minimize oxidative damage in the brain $(55,56)$.

In the present work, the neuroprotective activity of EGCG and the synthesized monoglucosides $\mathbf{1}$ and $\mathbf{2}$ toward human SH-S5Y5 neurons was tested in vitro. Previously we demonstrated that EGCG and its glucosides were not toxic for the cells (Figure 4A). Then, the neuroprotective activity in the presence of $\mathrm{H}_{2} \mathrm{O}_{2}$ was tested at the same compound concentrations $(1,10$, and $100 \mu \mathrm{M})$ 

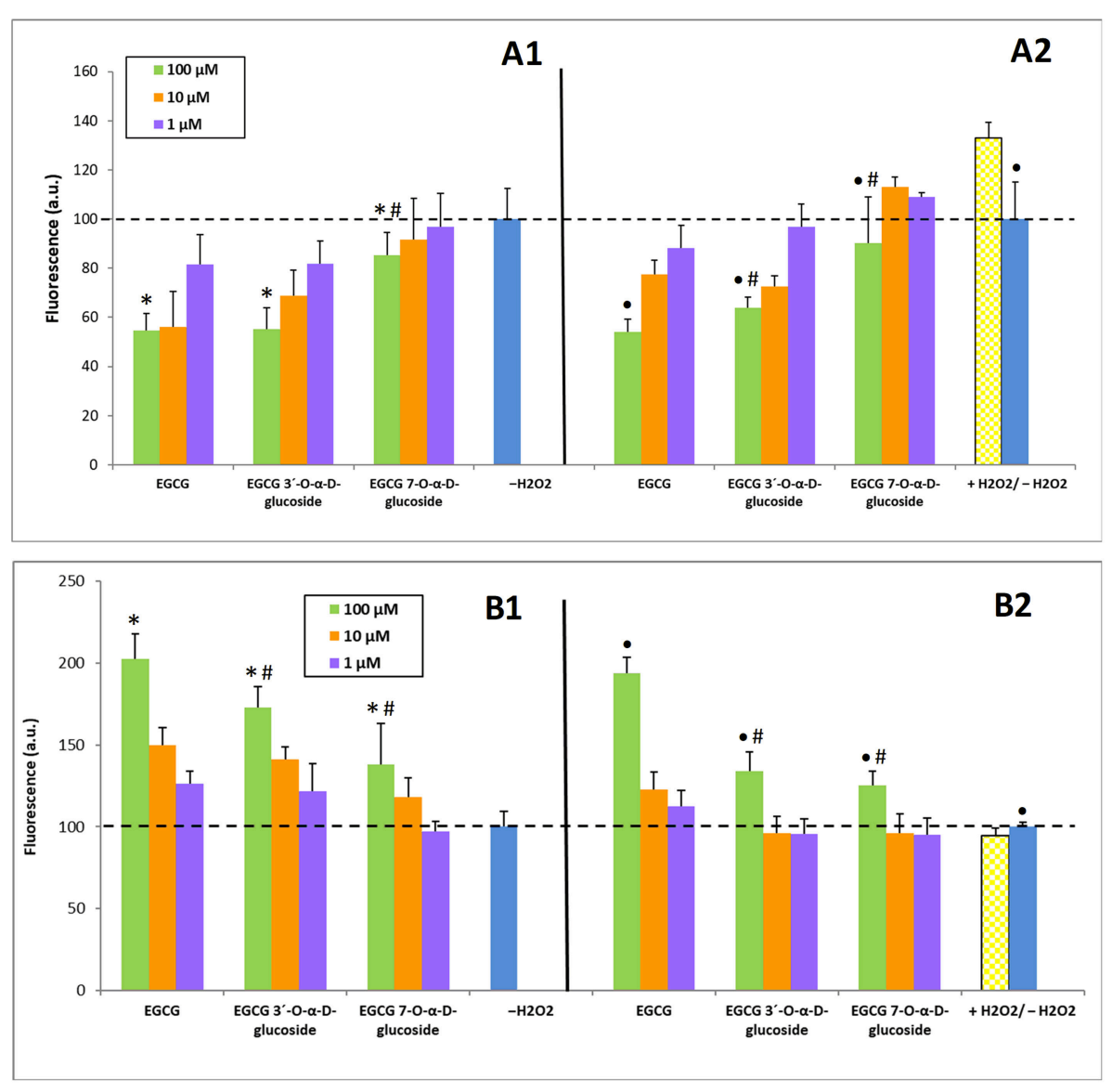

FIGURE 5 | Capacity of EGCG and its $\alpha$-glucosides 1 and $\mathbf{2}$ on SH-SY5Y neuronal cells to: (A) Alleviate intracellular ROS levels; (B) Enhance intracellular REDOX activity. (A1, B1) Incubation (6h) with the compounds without $\mathrm{H}_{2} \mathrm{O}_{2}$ treatment; (A2, B2) Pre-incubation $(2 \mathrm{~h})$ with the compounds followed by incubation $(2 \mathrm{~h})$ with $100 \mu \mathrm{M} \mathrm{H}_{2} \mathrm{O}_{2}$. The values are normalized to the experiments in absence of $\mathrm{H}_{2} \mathrm{O}_{2}\left(-\mathrm{H}_{2} \mathrm{O}_{2}\right)$. The data is expressed as mean $\pm \mathrm{SD}\left(n=8,{ }^{*} p<0.05\right.$ vs. $-\mathrm{H}_{2} \mathrm{O}_{2}$ group; $\bullet p<0.05$ vs. $+\mathrm{H}_{2} \mathrm{O}_{2}$ group; $\# p<0.05$ vs. EGCG $(100 \mu \mathrm{M})$ group).

(Figure 6). Values above 100\% indicated neuroprotection. EGCG and its glucoside 1 showed a dose-dependent behavior increasing cells viability after exposure to hydrogen peroxide. In particular, the viability increased 2.75 -fold, referred to the cells treated with $\mathrm{H}_{2} \mathrm{O}_{2}$, in the presence of $100 \mu \mathrm{M}$ of the $3^{\prime}$-glucoside, whilst EGCG increased 1.7-fold the viability of cells. This increased neuroprotection of monoglucoside 1 compared to EGCG might be related with their similar antioxidant activity (Figure 2) but the slower degradation of the $3^{\prime}$-glucoside (Figure 3 ). The enhancement of neuroprotective activity upon glycosylation was more significant than the reported with other related polyphenols such as hydroxytyrosol (13).

Both EGCG and its $3^{\prime}-\alpha$-D-glucoside exhibited better properties at $100 \mu \mathrm{M}$ than the $\alpha$-glucoside at C-7 of the Aring (compound 2). This result could be related with the lower antioxidant activity of the C-7 monoglucoside compared with EGCG and its derivative at C-3' (Figure 2). In this context, Xiao recently reported that several polyphenols with catechol or pyrogallol structure were unstable in cell culture medium such as DMEM in the absence of cells (57). For that reason, the different stability of EGCG and its glucosides (Figure 3), and in particular the stabilization effect upon glycosylation at C- $3^{\prime}$, could play a critical role in the bioactivity results presented in this work.

\section{CONCLUSION}

Two $\alpha$-glucosides of EGCG were enzymatically synthesized and their properties assayed. The major product $\mathbf{1}$ contained a glucosyl moiety at $\mathrm{C}-3^{\prime}$ in the B-ring and the minor compound 2 was glucosylated at C-7 of A-ring. The compound 1 exhibited more interesting properties than 2 . Thus, it displayed higher $\mathrm{pH}$ and thermal stability than EGCG, and a similar radical scavenging activity. It is remarkable that the viability of $\mathrm{H}_{2} \mathrm{O}_{2}$-treated human neurons increased 2.75-fold in the presence of monoglucoside 1, whilst EGCG only produced a 1.7 -fold enhancement. In conclusion, the $\alpha$-glucoside of EGCG at C-3' could be useful for nutraceutical, cosmetic and biomedical applications. However, to determine its full potential, further studies regarding the bioavailability and in vivo activity are necessary. 


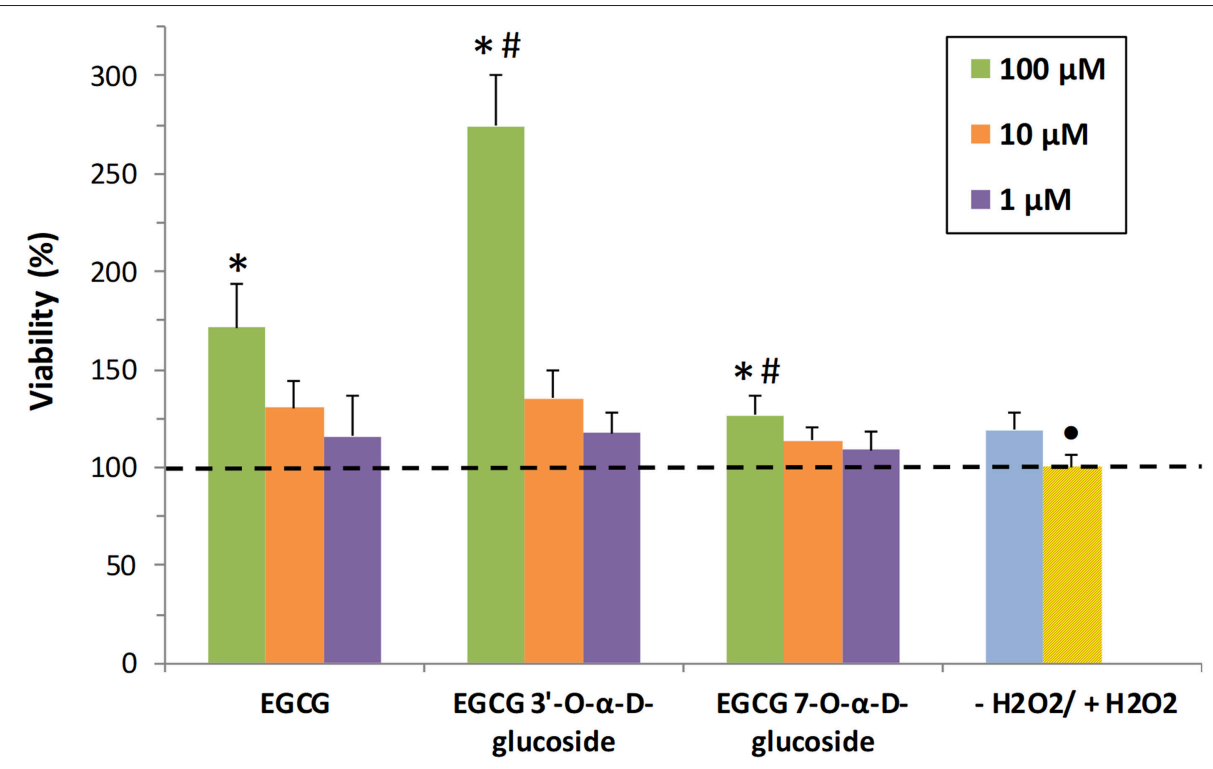

FIGURE 6 | In vitro analysis of neuroprotective activity of EGCG and its $\alpha$-glucosides $\mathbf{1}$ and $\mathbf{2}$ on SH-SY5Y neuronal cells. The values are referred to the viability of cells in presence of $\mathrm{H}_{2} \mathrm{O}_{2}\left(+\mathrm{H}_{2} \mathrm{O}_{2}\right)$. The data is expressed as mean $\pm \mathrm{SD}\left(n=8,{ }^{*} p<0.05\right.$ vs. $+\mathrm{H}_{2} \mathrm{O}_{2}$ group; $\bullet p<0.05$ vs. $-\mathrm{H}_{2} \mathrm{O}_{2}$ group; $\# p<0.05$ vs. EGCG $(100 \mu \mathrm{M})$ group).

\section{AUTHOR CONTRIBUTIONS}

FP, JM, and $\mathrm{AB}$ conceived and designed the experiments. JG-A and PP performed most of the experiments. FP and JM wrote the paper, which was improved by the rest of authors.

\section{FUNDING}

This work was supported by a grant from the Spanish Ministry of Economy and Competitiveness (BIO2016-76601-C3-1-R).

\section{ACKNOWLEDGMENTS}

We thank Ramiro Martinez (Novozymes A/S) for supplying Toruzyme and for critical suggestions. We thank the support of COST-Action CM1303 on Systems Biocatalysts. We acknowledge support of the publication fee by the CSIC Open Access Publication Support Initiative through its Unit of Information Resources for Research (URICI).

\section{REFERENCES}

1. Quideau S, Deffieux D, Douat-Casassus C, Pouységu L. Plant polyphenols: chemical properties, biological activities, and synthesis. Angew Chem Int Ed. (2011) 50:586-621. doi: 10.1002/anie.201000044

2. Pandey KB, Rizvi SI. Recent advances in health promoting effect of dietary polyphenols. Curr Nutr Food Sci. (2012) 8:254-64. doi: $10.2174 / 157340112803832228$

3. Shahidi F. Nutraceuticals, functional foods and dietary supplements in health and disease. J Food Drug Anal. (2012) 20:226-30.

4. Mojzer EB, Hrnčič MK, Škerget M, Knez Ž, Bren U. Polyphenols: extraction methods, antioxidative action, bioavailability and anticarcinogenic effects. Molecules. (2016) 21:E901. doi: 10.3390/molecules21070901

5. Serra A, Maci A, Romero MP, Valls J, Bladé C, Arola L, et al. Bioavailability of procyanidin dimers and trimers and matrix food effects in in vitro and in vivo models. Br J Nutr. (2010) 103:944-52. doi: 10.1017/S0007114509 992741

6. Weignerova L, Kren V. Enzymatic processing of bioactive glycosides from natural sources. Top Curr Chem. (2010) 295:121-46. doi: 10.1007/128_2010_51

7. Lepak A, Gutmann A, Kulmer ST, Nidetzky B. Creating a water-soluble resveratrol-based antioxidant by site-selective enzymatic glucosylation. ChemBioChem. (2015) 16:1870-4. doi: 10.1002/cbic.201500284

8. Medina I, Alcantara D, Gonzalez MJ, Torres P, Lucas R, Roque J, et al. Antioxidant activity of resveratrol in several fish lipid matrices: effect of acylation and glucosylation. J Agric Food Chem. (2010) 58:9778-86. doi: 10.1021/jf101472n

9. Nadim M, Auriol D, Lamerant-Fayel N, Lefe F, Dubanet L, Redziniak $\mathrm{G}$, et al. Improvement of polyphenol properties upon glucosylation in a UV-induced skin cell ageing model. Int J Cosmet Sci. (2014) 36:579-87. doi: $10.1111 /$ ics. 12159

10. Hollman PCH, Bijsman MNCP, Van Gameren Y, Cnossen EPJ, De Vries JHM, Katan MB. The sugar moiety is a major determinant of the absorption of dietary flavonoid glycosides in man. Free Radical Res. (1999) 31:569-73. doi: 10.1080/10715769900301141

11. Vrba J, Kren V, Vacek J, Papouskova B, Ulrichova J. Quercetin, quercetin glycosides and taxifolin differ in their ability to induce AhR activation and cypla1 expression in HepG2 cells. Phytother Res. (2012) 26:1746-52. doi: $10.1002 /$ ptr.4637

12. Makino T, Shimizu R, Kanemaru M, Suzuki Y, Moriwaki M, Mizukami H. Enzymatically modified isoquercitrin, $\alpha$-oligoglucosyl quercetin 3-Oglucoside, is absorbed more easily than other quercetin glycosides or aglycone after oral administration in rats. Biol Pharm Bull. (2009) 32:2034-40. doi: $10.1248 / \mathrm{bpb} .32 .2034$

13. Nieto-Domínguez M, De Eugenio LI, Peñalver P, Belmonte-Reche E, Morales JC, Poveda A, et al. Enzymatic synthesis of a novel neuroprotective 
hydroxytyrosyl glycoside. J. Agric. Food Chem. (2017) 65:10526-33. doi: 10.1021/acs.jafc.7b04176

14. Arts ICW, Sesink ALA, Faassen-Peters M, Hollman PCH. The type of sugar moiety is a major determinant of the small intestinal uptake and subsequent biliary excretion of dietary quercetin glycosides. Br J Nutr. (2004) 91:841-7. doi: 10.1079/BJN20041123

15. Perez-Vizcaino F, Duarte J, Santos-Buelga C. The flavonoid paradox: conjugation and deconjugation as key steps for the biological activity of flavonoids. J Sci Food Agric. (2012) 92:1822-5. doi: 10.1002/jsfa.5697

16. Gonzales GB, Van Camp J, Vissenaekens H, Raes K, Smagghe G, Grootaert C. Review on the use of cell cultures to study metabolism, transport, and accumulation of flavonoids: from mono-cultures to coculture systems. Compr Rev Food Sci Food Saf. (2015) 14:741-54. doi: 10.1111/1541-4337.12158

17. Raab T, Barron D, Arce Vera F, Crespy V, Oliveira M, Williamson G. Catechin glucosides: occurrence, synthesis, and stability. J Agric Food Chem. (2010) 58:2138-49. doi: 10.1021/jf9034095

18. Szeja W, Grynkiewicz G, Rusin A. Isoflavones, their glycosides and glycoconjugates. Synthesis and biological activity. Curr Org Chem. (2017) 21:218-35. doi: 10.2174/1385272820666160928120822

19. Lucas R, Alcantara D, Morales JC. A concise synthesis of glucuronide metabolites of urolithin-B, resveratrol, and hydroxytyrosol. Carbohydr Res. (2009) 344:1340-6. doi: 10.1016/j.carres.2009.05.016

20. Torres P, Poveda A, Jimenez-Barbero J, Parra JL, Comelles F, Ballesteros AO, et al. Enzymatic synthesis of $\alpha$-glucosides of resveratrol with surfactant activity. Adv Synth Catal. (2011) 353:1077-86. doi: 10.1002/adsc.201000968

21. Falomir E, Lucas R, Peñalver P, Martí-Centelles R, Dupont A, Zafra-Gómez A, et al. Cytotoxic, antiangiogenic and antitelomerase activity of glucosyl- and acyl- resveratrol prodrugs and resveratrol sulfate metabolites. ChemBioChem. (2016) 17:1343-8. doi: 10.1002/cbic.201600084

22. González-Alfonso J, Rodrigo-Frutos D, Belmonte-Reche E, Peñalver P, Poveda A, Jiménez-Barbero J, et al. Enzymatic synthesis of a novel pterostilbene $\alpha$-glucoside by the combination of cyclodextrin glucanotransferase and amyloglucosidase. Molecules. (2018) 23:1271. doi: $10.3390 /$ molecules 23061271

23. Plou FJ, Gómez de Segura A, Ballesteros A. Application of glycosidases and transglycosidases for the synthesis of oligosaccharides. In: Polaina J, and Andrew P, editors. Maccabe. Industrial enzymes: Structure, Function and Application. New York, NY: Springer (2007). p. 141-57.

24. Xu L, Qi T, Xu L, Lu L, Xiao M. Recent progress in the enzymatic glycosylation of phenolic compounds. J Carbohydr Chem. (2016) 35:1-23. doi: 10.1080/07328303.2015.1137580

25. Miguez N, Ramirez-Escudero M, Gimeno-Perez M, Poveda A, JimenezBarbero J, Ballesteros AO, et al. Fructosylation of hydroxytyrosol by the $\beta$ fructofuranosidase from Xanthophyllomyces dendrorhous: insights into the molecular basis of the enzyme specificity. ChemCatChem. (2018) 10:4878-87. doi: 10.1002/cctc.201801171

26. Grzesik M, Naparło K, Bartosz G, Sadowska-Bartosz I. Antioxidant properties of catechins: comparison with other antioxidants. Food Chem. (2018) 241:480-92. doi: 10.1016/j.foodchem.2017.08.117

27. Higdon JV, Frei B. Tea catechins and polyphenols: health effects, metabolism, and antioxidant functions. Crit Rev Food Sci Nutr. (2003) 43:89-143. doi: 10.1080/10408690390826464

28. Manohar M, Fatima I, Saxena R, Chandra V, Sankhwar PL, Dwivedi A. (-)-Epigallocatechin-3-gallate induces apoptosis in human endometrial adenocarcinoma cells via ROS generation and p38 MAP kinase activation. $J$ Nutr Biochem. (2013) 24:940-7. doi: 10.1016/j.jnutbio.2012.06.013

29. Naponelli V, Ramazzina I, Lenzi C, Bettuzzi S, Rizzi F. Green tea catechins for prostate cancer prevention: present achievements and future challenges. Antioxidants. (2017) 6:E26. doi: 10.3390/antiox6020026

30. Falcinelli SD, Shi MC, Friedlander AM, Chua J. Green tea and epigallocatechin-3-gallate are bactericidal against Bacillus anthracis. FEMS Microbiol Lett. (2017) 364:fnx127. doi: 10.1093/femsle/fnx127

31. Wu YR, Choi HJ, Kang YG, Kim JK, Shin JW. In vitro study on anti-inflammatory effects of epigallocatechin-3-gallate-loaded nano- and microscale particles. Int J Nanomed. (2017) 12:7007-13. doi: 10.2147/IJN.S146296
32. Wang R, Zhou W, Jiang X. Reaction kinetics of degradation and epimerization of epigallocatechin gallate (EGCG) in aqueous system over a wide temperature range. J Agric Food Chem. (2008) 56:2694-701. doi: 10.1021/jf0730338

33. Lambert JD, Sang S, Hong J, Kwon SJ, Lee MJ, Ho CT, et al. Peracetylation as a means of enhancing in vitro bioactivity and bioavailability of epigallocatechin3-gallate. Drug Metab Dispos. (2006) 34:2111-6. doi: 10.1124/dmd.106.011460

34. Sang S, Lee MJ, Hou Z, Ho CT, Yang CS. Stability of tea polyphenol ()-epigallocatechin-3-gallate and formation of dimers and epimers under common experimental conditions. J Agric Food Chem. (2005) 53:9478-84. doi: $10.1021 /$ f0519055

35. Moon YH, Kim G, Lee JH, Jin XJ, Kim DW, Kim D. Enzymatic synthesis and characterization of novel epigallocatechin gallate glucosides. $J$ Mol Catal B Enzym. (2006) 40:1-7. doi: 10.1016/j.molcatb.2006.01.030

36. Noguchi A, Inohara-Ochiai $M$, Ishibashi $N$, Fukami $H$, Nakayama $T$, Nakao M. A novel glucosylation enzyme: molecular cloning, expression, and characterization of Trichoderma viride JCM22452 $\alpha$-amylase and enzymatic synthesis of some flavonoid monoglucosides and oligoglucosides. J Agric Food Chem. (2008) 56:12016-24. doi: 10.1021/jf801712g

37. Kitao S, Matsudo T, Horiuchi T, Sekine H, Saitoh M. Enzymatic syntheses of two stable (-)-epigallocatechin gallate-glucosides by sucrose phosphorylase. Biosci Biotechnol Biochem. (1995) 59:2167-9. doi: 10.1271/bbb.59.2167

38. Moon YH, Lee JHA, Ahn JS, Nam SH, Oh DK, Park DH, et al. Synthesis, structure analyses, and characterization of novel epigallocatechin gallate (EGCG) glycosides using the glucansucrase from Leuconostoc mesenteroides B-1299CB. J Agric Food Chem. (2006) 54:1230-7. doi: 10.1021/jf052359i

39. Kim J, Nguyen TTH, Kim NM, Moon YH, Ha JM, Park N, et al. Functional properties of novel epigallocatechin gallate glucosides synthesized by using dextransucrase from Leuconostoc mesenteroides B-1299CB4. J Agric Food Chem. (2016) 64:9203-13. doi: 10.1021/acs.jafc.6b04236

40. Gonzalez-Alfonso JL, Leemans L, Poveda A, Jiménez-Barbero J, Olmo Ballesteros A, Plou FJ. Efficient $\alpha$-glucosylation of epigallocatechin gallate catalyzed by cyclodextrin glucanotransferase from Thermoanaerobacter sp. J. Agric. Food Chem. (2018) 66:7402-8 doi: 10.1021/acs.jafc.8b02143

41. Nanjo F, Goto K, Seto R, Suzuki M, Sakai M, Hara Y. Scavenging effects of tea catechins and their derivatives on 1,1-diphenyl-2-picrylhydrazyl radical. Free Radical Biol Med. (1996) 21:895-902. doi: 10.1016/0891-5849(96)00237-7

42. Nanjo F, Mori M, Goto K, Hara Y. Radical scavenging activity of tea catechins and their related compounds. Biosci Biotechnol Biochem. (1999) 63:1621-3. doi: $10.1271 /$ bbb.63.1621

43. Valcic S, Muders A, Jacobsen NE, Liebler DC, Timmermann BN. Antioxidant chemistry of green tea catechins. Identification of products of the reaction of (-)-epigallocatechin gallate with peroxyl radicals. Chem Res Toxicol. (1999) 12:382-6. doi: 10.1021/tx990003t

44. Zimeri J, Tong CH. Degradation kinetics of (-)-epigallocatechin gallate as a function of $\mathrm{pH}$ and dissolved oxygen in a liquid model system. J Food Sci. (1999) 64:753-8. doi: 10.1111/j.1365-2621.1999.tb15905.x

45. Chen ZY, Zhu QY, Tsang D, Huang Y. Degradation of green tea catechins in tea drinks. J Agric Food Chem. (2001) 49:477-82. doi: 10.1021/jf000877h

46. Hatano T, Hori M, Kusuda M, Ohyabu T, Ito H, Yoshida T. Characterization of the oxidation products of (-)-epigallocatechin gallate, a bioactive tea polyphenol, on incubation in neutral solution. Heterocycles. (2004) 63:1547-54. doi: 10.3987/COM-04-10039

47. Farhan M, Khan HY, Oves M, Al-Harrasi A, Rehmani N, Arif H, et al. Cancer therapy by catechins involves redox cycling of copper ions and generation of reactive oxygenspecies. Toxins. (2016) 8:37. doi: 10.3390/ toxins 8020037

48. Tao L, Park JY, Lambert JD. Differential prooxidative effects of the green tea polyphenol, (-)-epigallocatechin-3-gallate, in normal and oral cancer cells are related to differences in sirtuin 3 signaling. Mol Nutr Food Res. (2015) 59:203-11. doi: 10.1002/mnfr.201400485

49. Lorenz M. Cellular targets for the beneficial actions of tea polyphenols. Am J Clin Nutr. (2013) 98:1642S-1650S. doi: 10.3945/ajcn.113.058230

50. González-Sarrías A, Núñez-Sánchez MÁ, Tomás-Barberán FA, Espín JC. Neuroprotective effects of bioavailable polyphenol-derived metabolites against oxidative stress-induced cytotoxicity in human neuroblastoma SH-SY5Y cells. J Agric Food Chem. (2017) 65:752-8. doi: 10.1021/acs. jafc.6b04538 
51. Hou RR, Chen JZ, Chen H, Kang XG, Li MG, Wang BR. Neuroprotective effects of (-)-epigallocatechin-3-gallate (EGCG) on paraquatinduced apoptosis in PC12 cells. Cell Biol Int. (2008) 32:22-30. doi: 10.1016/j.cellbi.2007.08.007

52. Zhang H, Wang JR, Yau LF, Ho HM, Chan CL, Hu P, et al. A cellular lipidomic study on the $\mathrm{A} \beta$-induced neurotoxicity and neuroprotective effects of EGCG by using UPLC/MS-based glycerolipids profiling and multivariate analysis. Mol BioSyst. (2012) 8:3208-15. doi: 10.1039/c2mb25126d

53. Kian K, Khalatbary AR, Ahmadvand H, Karimpour Malekshah A, Shams Z. Neuroprotective effects of (-)-epigallocatechin-3-gallate (EGCG) against peripheral nerve transection-induced apoptosis. Nutr Neurosci. (2018). doi: 10.1080/1028415X.2017.1419542. [Epub ahead of print].

54. Singh NA, Mandal AKA, Khan ZA. Potential neuroprotective properties of epigallocatechin-3-gallate (EGCG). Nutr J. (2016) 15:60. doi: 10.1186/s12937-016-0179-4

55. Unno K, Takabayashi F, Yoshida H, Choba D, Fukutomi R, Kikunaga N, et al. Daily consumption of green tea catechin delays memory regression in aged mice. Biogerontology. (2007) 8:89-95. doi: 10.1007/s10522-006-9036-8
56. Schaffer S, Asseburg H, Kuntz S, Muller WE, Eckert GP. Effects of polyphenols on brain ageing and Alzheimer's disease: focus on mitochondria. Mol Neurobiol. (2012) 46:161-78. doi: 10.1007/s12035-0 12-8282-9

57. Xiao J. Stability of dietary polyphenols: it's never too late to mend? Food Chem Toxicol. (2018) 119:3-5. doi: 10.1016/j.fct.2018.03.051

Conflict of Interest Statement: The authors declare that the research was conducted in the absence of any commercial or financial relationships that could be construed as a potential conflict of interest.

Copyright $\odot 2019$ Gonzalez-Alfonso, Peñalver, Ballesteros, Morales and Plou. This is an open-access article distributed under the terms of the Creative Commons Attribution License (CC BY). The use, distribution or reproduction in other forums is permitted, provided the original author(s) and the copyright owner(s) are credited and that the original publication in this journal is cited, in accordance with accepted academic practice. No use, distribution or reproduction is permitted which does not comply with these terms. 